\title{
Autocommunication in semiotic systems: 40 years after the Theses on the Semiotic Study of Cultures (Tartu Summer School in Semiotics 2013)
}

\section{Anti Randviiir}

Theses on the Semiotic Study of Cultures first appeared 40 years ago, in $1973 .{ }^{2}$ The title of the publication indicates that alongside with outlining a conditionally novel semiotic approach the authors were discussing the Study of Cultures. This means that besides establishing the theoretical boundary of semiotics of culture, the publication simultaneously assembled an actual methodological start-up toolkit for practical study of culture and individual cultural phenomena.

There is a quintessential coincidence between semiotics of culture, the TartuMoscow school, and the Theses which places this triad amongst both the important and the amusing ones in the story of humanities. Besides being considered as a classic in the history of semiotics and marking the start of the already born trend of semiotics of culture, Theses is an example to be followed in its generation as a result of an international collective effort. The topic of the current year's summer school involved a seemingly minute nuance, but one that connected the times of the Theses with this day both formally and in essence. The Study of Cultures gave birth to the semiotics of culture on the basis of so-to-speak negotiated semiotics, and ever since today it is hardly possible to find similar examples. At most, we can speak of some semiotic subtrends associated with individual visions, and decide on theses on (specific or general) semiotics presented by individual scholars.

Taking the example of the Theses from the past, and reflecting over it together with its influences across the time up to today, the semiotic circles might take up reflective autocommunication in order to set future steps in organizing both the paradigm of semiotics and communicate the institution of semiotics to neighbouring paradigms. It is noteworthy that autocommunication in the semiotics of today's Tartu has

1 Author's address: Department of Semiotics, University of Tartu, Jakobi St. 2, 51014 Tartu, Estonia; e-mail: anti.randviir@ut.ee.

2 See bibliography in Salupere et al. 2013. 
already moved towards communication between the soft (semiotic) and hard (physical) sciences. Bridging cultural semiotics, biosemiotics, and sociosemiotics, new perspectives can be envisaged for a qualitatively new Tartu semiotics, offering the general semiotic paradigm a holistic theoretical ground on which to build a coherent methodological toolkit for the study of man in his diverse environments.

On the object-level, man's communication with his surroundings leads to further autocommunication and reconceptualization of himself as a semiotic subject. Thus, here we also have a meeting point of autocommunication and reflection, or - self-description. Practical holistic study of culture and semiotic subjects in their self-descriptive, autocommunicative, and communicative functioning leads to simultaneous holistic tendencies also on the metalevel. From here we must follow an apparent clue: self-description brings together the generation, maintenance, and transmission of information - again, both on the object-level and on the metalevel. This aspect helps to recognize the value of quite a universal metalanguage of the Tartu-Moscow School for the description of the basic functioning of semiotic mechanisms or modelling systems.

This year, to celebrate the 40th anniversary of Theses on the Semiotic Study of Cultures, the organizers would call for reflections on the context and co-texts leading to and from that milestone in semiotic studies. The contemporary stage of the humanities and the social sciences, reaching its middle age as also the Theses, brought forth the need to conceptualize developments in the semiotics of culture ever since the Theses, as also to highlight clues to its applications in neighbouring disciplines and in trends it has brought forth. Ecomapping the so-called hard and soft sciences in the context of semiotics also seemed to offer a possibility to position today's Tartu semiotics within the semiotics of culture, as also in the general paradigm of semiotics and other disciplines on the timeline associated with the 'ground zero' of the Theses. In the frame of the Summer School, this implied contemplation on communication and autocommunication as a specific topic in semiotics of culture - also in exemplary case studies as a possibility to open up a discussion on the semiotics of culture either as a coherent monolith or as an open cumulative paradigm developed through ad hoc research.

\section{The event}

This year, the Summer School dedicated to the anniversary of the Theses, took place at Käariku in South Estonia, the place that offered its genius loci to the original first gatherings of scholars whose activities led both to the birth of the Theses and the semiotics of culture in general. ${ }^{3}$

3 On the history of Tartu semiotics Summer Schools, see Kull, Salupere, Torop, Lotman 2011. 
In accordance with to the main focus of the summer school, we also tried to facilitate autocommunication between the participants, and simultaneously to advance the idea of the summer school as a form of congregation. Thus all presentations, round tables and dialogues were taking place in a single auditorium and in one session attended by around eighty participants. Looking backwards, this was a logical continuation to the original summer schools of the 1960s, and helped to bring together scholars from very diverse areas into a united, if not cohered, discourse. Simultaneously, students from numerous universities from many countries had an opportunity to really experience a full-scale training that lasted from August 18 until August 23, 2013. During these days, the main topics reflected in the keywords, were obviously concerned with recalling and reflecting on Theses on the Semiotic Study of Culture on the one hand, and, on the other hand, dealing with a selection of the most characteristic and influential issues of the semiotics of culture ever since its birth. Among the latter, the programme centred on Space/System/Model, Culture/ Art/Education/Environment, History/Identity/Subject. The following argument is largely a reflection on the basis of the presentations made, and attempts to provide a rough overview of the general discourse of the Summer School.

Discussion of the past and the present of the Theses naturally involved pondering about the context of the emergence of the Tartu-Moscow School of semiotics of culture (presentations by M. Tamm, T. Boyko, T. Adkins, R. Gramigna, K. Kull, E. Velmezova). As revealed in the presentations and also as disclosed during the round-table discussions, that context had several dimensions. One of those - and probably the one most commonly referred to - was political, implying first hand both intellectual, communicative and locational seclusion of the so-to-speak first generation of the School (referring, formally, to authors of the Theses and the first dozens of co-authors of Sign Systems Studies). Such isolation of the first semioticians of culture from the international stage was accompanied by the detachment from the mainstream, and usually politically guided, scholarly activity of the group. These processes led to their inclination towards the outskirts - or periphery, if you will - of the Soviet official academic activities not only conceptually, but also brought along the development of semiotics at and around Tartu and Kääriku. As claimed by even Juri Lotman, the emergence of semiotics in Tartu was not a coincidence, and had to do with a unique overlap of physical and cultural space. Semiotics of culture, a trend belonging to the very core of semiotics today, came into being in the periphery in so many aspects of the Soviet reality, yet simultaneously brought together specialists eminent in their original fields. Thus it was not a mere twist of fate that a new paradigm of thought had to be born, and that a keyword to characterize such a congregation was autocommunication - a notion so central for the later semiotics of culture, and a term to characterize the intellectual 
processes forming the boundaries of the future paradigm by an intellectual synthesis of individual minds.

Autocommunication thus caught the attention of the organizers as a determining notion for both the Theses and semiotics of culture, and was discussed in its many aspects ranging from being a process leading to cultural semiotics up to a serving as a connector of the latter and its neighbouring disciplines (presentations by P. Grzybek, Z. Wasik, A. Randviir, L. Han, R. Magnus, T. Raudla, D. Teters).

The birth of semiotics of culture and the composition of the Theses had to do with the assembly of representatives of dissimilar disciplines. The combination of their intellectual backgrounds and the actual situation of a real paradigmatic shift in the very sense of the notion meant that semiotics of culture came into being already as an interdisciplinary phenomenon, for that was simply a historical, intellectual, and heuristic necessity. In a manner of speaking, it was a filtration of several existing trends in the humanities and social sciences so that they were brought together by the authors of the Theses and other members of the Tartu-Moscow group, and synthesized into a specific mode of thought under the name of semiotics of culture. Thus, semiotics of culture was a kind of a shopping cart of intellectual efforts carried out by the founders of the School, a cart that was available for them in the global mall, and filled with what they could choose or what they were able to pick up either in their political, linguistic, monetary or other kind of currency. This, apparently, was not an insignificant detail connecting semiotics of culture - in what may be a roundabout way - with other disciplines so as the latter were, at those times, associated with psychology, sociology and anthropology. Apparently, the inherent interdisciplinarity of semiotics of culture that was, in a way, a prerequisite, basic condition and principle of compilation, is also a simple reason to explain its spread into diverse application sites and fields in the ad hoc approach. Simultaneously, it is a way to see the widening of semiotics of culture into diverse disciplines and areas of study as terminological, methodological and theoretical loans and adaptations. And, third, it is a possibility to understand the potential of the semiotics of culture - as also semiotics in general - for the creation of not only interdisciplinary toolkits, but also transdisciplinary paradigm(s). Suchlike manifold interdisciplinary connections, loans, movements, compilations and applications alongside with both their historical roots and further rootings were noticed also at the Summer School both in the way they are concerned with the purely methodological level (presentations by A. Tucker, H. Chang, T. Maran), as well as ad hoc case studies (presentations by F. Bellentani, T. Pitkajärvi, M.-L. Madisson, A. Ventsel, O. Puumeister, K. Kaczmarczyk, M.-K. Lotman, M. Lotman). Similarly, attention was paid to certain key concepts of cultural semiotics so that they can be applied to diverse cultural phenomena and dimensions of human activity, thereby 
offering a novel viewpoint possibly alternating the essence of those objects and opening up their semiotic essence (presentations by T. Remm, A. Lagopoulos, K. Lagopoulou, A. Markoš, Ü. Pärli, E. Wasik, S. Salupere, O. Barabanov, E. Kourdis, L. Yoka).

As it has been a uniting feature of most congregations in semiotics, this Summer School did not escape the topic of the semiotic threshold. This, however, could not be surprising, as if not the whole paradigm of semiotics of culture, then at least most of its main research topics and basic assumptions have always been whirling around issues connected with the notion of the boundary - be the latter concerned with relations between culture and nature, cultural and non-cultural, textual and extratextual, the inside and outside of the semiosphere. Thus, discussions in presentations and at round table sessions often inspected the topic of the beginning of semiosis as having to do with the emergence of consciousness that leads to the interpretation of narratives and the creation of textual phenomena, texts, and finally sociocultural systems (presentations by C. Hernandez, P. Cobley, B. v. Heusden). Simultaneously with the object level, the subject of distinguishing the semiotic matter from the non-semiotic realm was recognized on the metalevel in connection with the frontiers of cultural semiotics, as well as the future developments of it as a paradigm (presentations by M. Lotman, P. Torop).

Needless to say, the above general overview of the topics discussed at Käariku is but an arbitrary attempt to cover all that extensive gathering contained, and association of individual presentations with quite specific fragments in the overall discussion should be seen as quite conditional and subjective. Likewise, autocommunication as the focal issue of this Summer School was simply one of the key notions and a frequently emerging theme in semiotics of culture selected for this year's discussions. Yet, inasmuch as autocommunication so clearly indicates the spatial and temporal dimensions of semiotic phenomena and until now, in connection with the research of the Tartu-Moscow School, it is mostly spatial issues that have been cast light on, the participants agreed upon the necessity to start bringing the temporal dimension of semiosis and semiotic phenomena onto the table as well. Therefore, our next gathering will try to centre on temporality in the culturosemiotic treatment of semiosis up to the manifold matters concerned with cultural dynamism, regarding also metalinguistic developments in metacultures.

\section{References}

Kull, Kalevi; Salupere, Silvi; Torop, Peeter; Lotman, Mihhail 2011. The institution of semiotics in Estonia. Sign Systems Studies 39(2/4): 314-342.

Salupere, Silvi; Torop, Peeter; Kull, Kalevi (eds.) 2013. Beginnings of the Semiotics of Culture. (Tartu Semiotics Library 13.) Tartu: University of Tartu Press. 